\title{
SCREENING FOR CHROMOSOMAL ANOMALIES IN THE FIRST TRIMESTER: A REPORT ON THE FIRST YEAR OF PROSPECTIVE SCREENING FOR CHROMOSOMAL ANOMALIES IN THE FIRST TRIMESTER IN THE CZECH REPUBLIC
}

\author{
Ishraq Dhaifalaha, Jiri Santavy ${ }^{\mathrm{a}}$, Jana Zapletalova ${ }^{\mathrm{b}}$ \\ ${ }^{a}$ Department of Medical Genetics and Fetal Medicine, Faculty of Medicine and Dentistry, Palacky University and University \\ Hospital, Olomouc, Czech Republic \\ ${ }^{b}$ Department of Biophysics, Faculty of Medicine and Dentistry, Palacky University, Olomouc \\ e-mail:ishraq_dhaifalah@yahoo.com
}

Received: April 28, 2006; Accepted: November 1, 2006

Key words: First trimester screening/Nuchal translucency/Pregnancy-associated plasma protein-A (PAPP-A)/Free ß-human chorionic gonadotropin $(\beta-h C G)$

Background: The increase in maternal age in recent years has intensified the effort to develop early non-invasive methods for screening for trisomy 21 and other chromosomal abnormalities in prenatal diagnosis. In the first trimester of pregnancy, maternal age, fetal nuchal translucency (NT), maternal levels of free $\beta$ - human chorionic gonadotropin $(\beta-h C G)$ and pregnancy-associated plasma protein-A (PAPP-A) are used as screening markers. We evaluated the introduction of this method of screening for the first time in the Czech Republic.

Methods: it is a prospective study for one-year from the beginning of 2004. The risk of trisomy 21(Down's syndrome) was estimated for 686 singleton pregnancies. The specific risk was calculated using the Fetal Medicine Foundation software (FMF) by accredited sonographers. Karyotyping was offered to women with risk $\geq 1$ in 250 .

Results: In the population screened $18 \%$ of women were aged 35 and more. We found 2 cases of trisomy 21 and 1 case of trisomy 18 (Edward syndrome) resulting in a detection rate of $100 \%$ for trisomy 21 for a $5 \%$ false positive rate ( 33 of 683 ). The maternal age of the detected cases was 30,38 and 42 years.

Conclusion: Introduction of the first trimester screening to our clinic, reduced the number of invasive genetic testing from $18 \%$ to $5 \%$. First trimester screening for trisomy 21 and other aneuploidies has a high sensitivity with a low false positive rate and can be delivered in an efficient manner in a university hospital.

\section{INTRODUCTION}

In the last decade, it has become possible to observe many features of chromosomal abnormalities by ultrasound in the third month of intrauterine life. About $75 \%$ of trisomy 21 fetuses have increased NT thickness, $70 \%$ have absent nasal bone and $25 \%$ have maxillary hypoplasia ${ }^{1}$.

In the first trimester of pregnancy, screening by a combination of ultrasound markers and maternal serum $\beta$-hCG and PAPP-A can identify up to $97 \%$ of fetuses with trisomy 21 and other major chromosomal abnormalities ${ }^{2}$.

The vast majority of pregnant women prefer screening in the first, rather than in the second trimester ${ }^{3-5}$. As with all aspects of good clinical practice, those performing first trimester screening should be appropriately trained and their results subjected to external quality assurance ${ }^{6}$.

Prenatal diagnosis requires either amniocentesis from 15 weeks of pregnancy or chorionic villous sampling from 11 weeks. The procedure-related risk of miscarriage is the same for both procedures and it is less than $1 \%$. As a consequence of screening, invasive testing is carried out only in pregnancies considered to be at high-risk and by obstetricians skilled for ultrasonography detection of chromosomal abnormalities ${ }^{7,8}$. In this study we evaluated the introduction of this method of screening for providing a risk estimation of chromosomal abnormalities in the first trimester at the Medical Genetic and Fetal Medicine Department of the University Hospital in Olomouc over a year for the first time in the Czech Republic.

The mean outcome measures were the uptake of screening, uptake of invasive testing, detection rate for fetal chromosomal abnormalities, false positive rate, and the distribution of maternal age and CRL (Crown-Rump Length) in the screened population.

\section{METHODS}

It is a prospective study of all women booked for screening at our department. They were given an appointment to attend the antenatal clinic for the first time at around 12 weeks. Screening using the first trimester began in January 2004. Women were initially seen in the community by their obstetricians ( $99 \%$ of cases). They received an information leaflet about the first trimester 
screening tests that are available either from their obstetrician or with their initial booking appointment later. On attending the clinic at a specified appointment time, women have a consultation with the sonographers (obstetricians with a genetic background specialization) concerning the available tests and, if they elected to have prenatal screening for chromosomal anomalies, all relevant clinical information was recorded on the request forms. Adhering to confidentiality safeguards, the risks, benefits, objectives and procedures of the study were explained to study participants before each examination to protect human subjects and the respondents signed informed consent. After pre-test counseling, women opting into the screening program underwent US scanning to ascertain the gestational age. At the same time blood samples were taken for serum biochemical screening.

If the gestational age was between $11^{+0}-13^{+6}$ weeks, the fetal NT thickness and CRL were measured using standard procedures (www.fetalmedicine.com) by FMF certified sonographer or by well-trained sonographist working under the supervision of a certified one. A mini anomaly scan was also performed. The whole ultrasound process was completed within 15-20 minutes in 95\% of cases. Blood samples for biochemical screening were passed to the hospital laboratory. The serum was separated and analyzed for free $\beta$-hCG and PAPP-A using Immulite DPC 2000 (Diagnostic Products Corporation, Los Angeles, USA). If the gestational age was not enough advanced for screening, the women were booked for later dates. The results were immediately logged onto the fetal database and a composite risk report was produced. This report was then available for the midwife /counselor (according to the results) to discuss with the woman and appropriate further follow up and management was arranged. Patient-specific risks were calculated by a multivariate approach using population's parameters established by FMF $^{9}$. Women with an increased risk of $\geq 1$ in 250 for trisomy 21 or any other chromosomal abnormalities were offered chorionic villous sampling or amniocentesis for fetal karyotyping. Provisional results from quantitative PCR (polymerase chain reaction) were available within 48-72 hours and a final diagnosis by conventional karyotyping within three weeks.

All relevant clinical information was recorded on a networked fetal database (Astraia, Germany). A comprehensive review of completed data was done and data base information were prepared. Data analysis was then performed by the Statistical Department, Faculty of Medicine, Palacký University in Olomouc.

\section{RESULTS}

During a one-year period (12 January 2004 - 31 December 2004), a total of 686 women with singleton pregnancies were offered first trimester screening. The uptake of first trimester screening was $100 \%$. The population consisted of $99.6 \%$ Caucasian, $0.4 \%$ Asian. Of the screened population $55 \%$ were from the district of Olomouc, $10 \%$ from Přerov, $10 \%$ from Prostějov and the remaining $25 \%$ from other adjacent areas.

The median maternal age was 29 years (range 15 to 43 ) with $18 \%$ (120) over the age of 35 years and a distribution as shown in (Fig.1). Based on the maternal age distribution of pregnancies and the risk of trisomy 21 at 12 weeks, we expected 1.5 cases of trisomy 21 and 1.5 other chromosomal abnormalities in the study population.

The NT median was $1.6 \mathrm{~mm}$ (range 1.0-5.3) with a distribution shown in Fig. 2, it was above the $95^{\text {th }}$ percentile in $5.3 \%$. There was no failure to obtain a satisfactory NT thickness measurement by either trans-abdominal or trans-vaginal ultrasound on the first clinic visit, without necessitating a further clinic visit.

The median gestation was 88 days (range 78-97 days)

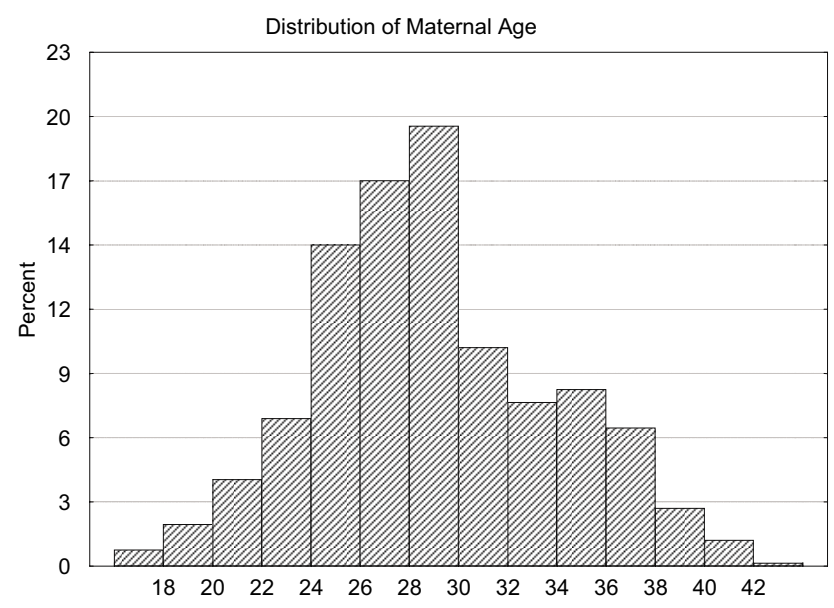

Fig. 1. Age distribution of the population screened

Table 1. Ultrasound and biochemical markers in the three identified women with chromosomal abnormalities.

\begin{tabular}{|c|c|c|c|c|c|c|}
\hline Age & $\begin{array}{c}\text { CRL } \\
(\mathrm{mm})\end{array}$ & $\begin{array}{c}\mathrm{NT} \\
(\mathrm{mm})\end{array}$ & $\begin{array}{c}\beta-\mathrm{hCG} \\
(\mathrm{MoM})\end{array}$ & $\begin{array}{c}\text { PAPP-A } \\
(\mathrm{MoM})\end{array}$ & Adjusted risk & Karyotype \\
\hline 30 & 63.6 & 4.2 & 0.16 & 0.21 & $1: 14$ & Trisomy 18 \\
\hline 38 & 68.0 & 1.8 & 1.80 & 0.20 & $1: 13$ & Trisomy 21 \\
\hline 42 & 64.7 & 2.4 & 1.90 & 0.12 & $1: 12$ & Trisomy 21 \\
\hline
\end{tabular}




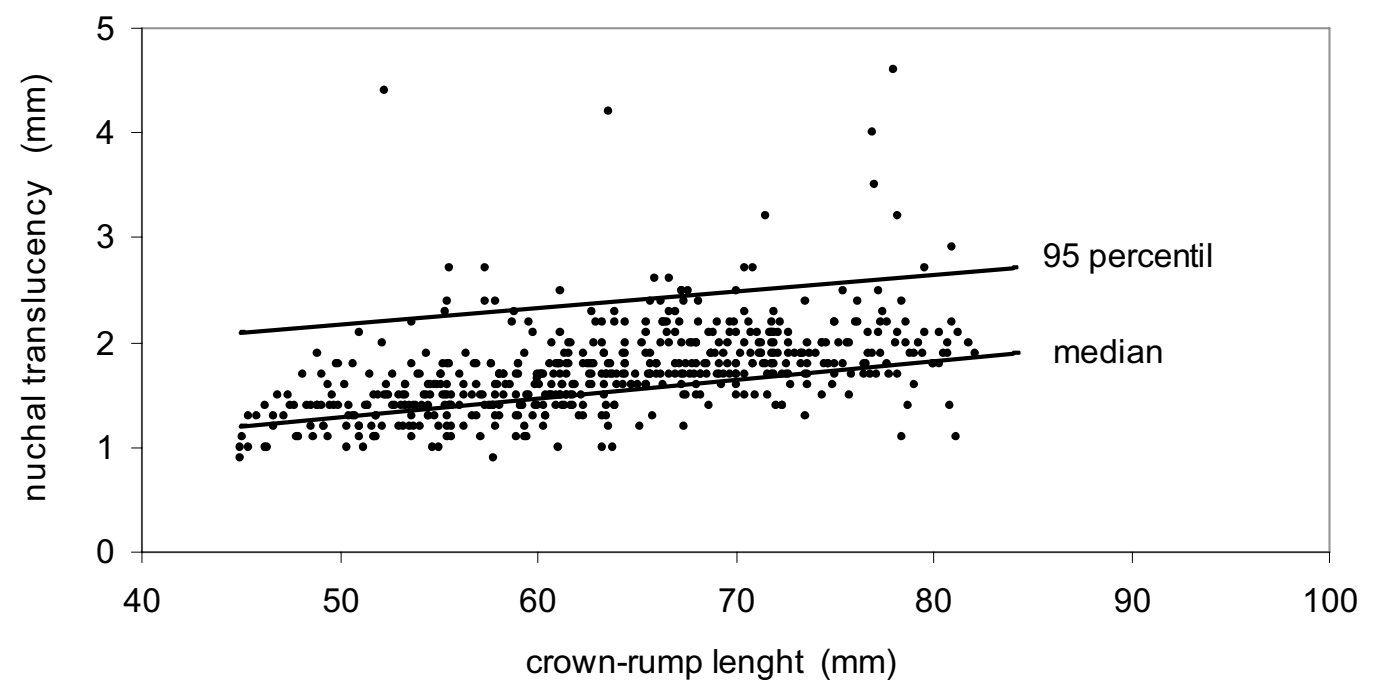

Fig. 2. Nuchal translucency for crown rump length plotted on the median and $95^{\text {th }}$ percentile of the range provided by FMF.

and the median CRL was $62 \mathrm{~mm}$ (range 45-82) with a distribution shown in Fig. 3.

The medians of free $\beta-\mathrm{hCG}$ and PAPP-A were $1.0 \mathrm{MoM}$ (multiple of medians) (range 1.0 to 10.5 ) and $1.0 \mathrm{MoM}$ (range 0.1-8.9) subsequently.

Of the women screened in the first trimester, $5 \%$ (36 of 686) had risks greater than $1: 250$ cut-off. After counseling those women $100 \%$ (36 of 36) accepted invasive testing. Chorionic villous sampling was the procedure chosen by $84 \%$ ( 29 of 36) of women requesting invasive testing, while $16 \%$ (6 of 36 ) decided to wait until 15 weeks for amniocentesis. One case of fetal loss occurred after chorionic villous sampling and none after amniocentesis.

Among the singleton study population, 3 aneuploidies were ascertained (Tab. 1). A combination of maternal age, fetal nuchal translucency thickness, maternal serum free $\beta$-hCG and PAPP-A identified $100 \%$ ( 2 of 2 ) of cases with trisomy $21,100 \%$ ( 1 of 1 ) with trisomy 18 , in total $100 \%$ ( 3 of 3) of all cases of aneuploidy. All women with an identified chromosomal anomaly elected to terminate the pregnancy.

For maternal age alone, $18 \%$ of the cases would have been identified for invasive testing; NT thickness, maternal age and the biochemistry had reduced this percentage to only $5 \%$ (36 of 683 ). In our program we have relied on ultrasonography at the 20-23 weeks anomaly scan to identify neural tube defect abnormalities ${ }^{10-12}$. We observed only one fetus with neural tube defect.

\section{DISCUSSION}

This study demonstrated the feasibility and efficacy of introducing first trimester screening for chromosomal abnormalities in a University Hospital. The uptake of first trimester screening was $100 \%$ and the uptake of invasive testing in the screen positive group was also $100 \%$ (3 of

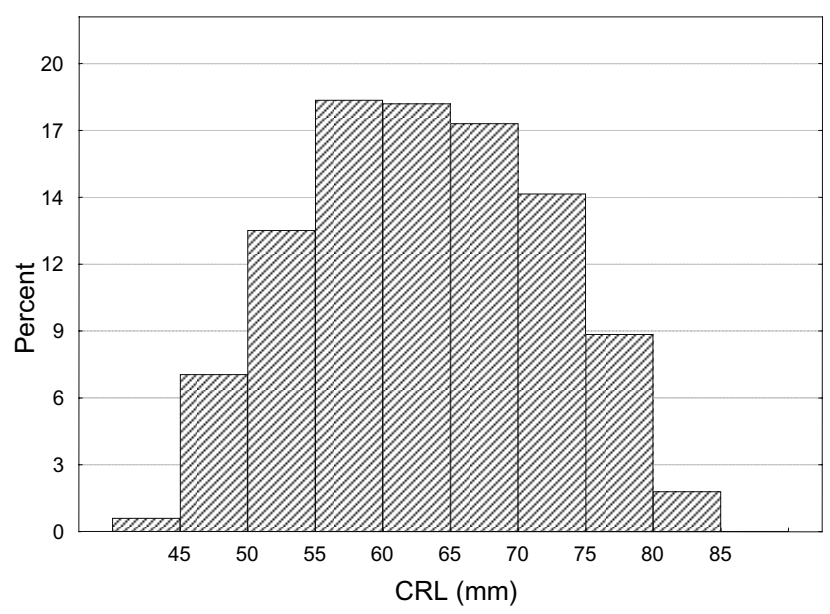

Fig. 3. Crown-rump length distribution of the population screened.

3). For a false positive rate of about $5 \%$ (33 of 663), the detection rate of trisomy 21 and other aneuploidies was $100 \%$. In the first trimester, the prevalence of trisomy 21 and other aneuploidies is considerably greater than at the second trimester or indeed at term. Our prevalence of 3 cases per 686 women is consistent with that expected from the maternal age profile of the screened population and the risk of trisomy 21 at 12 weeks of gestation ${ }^{13}$. We have included only singleton pregnancies because multiple pregnancies require a different algorithm for the assessment of their risk.

The importance of accurate risk estimates is shown by the reduction in the number of unnecessary invasive tests. An important additional finding was the diagnosis of the neural tube defect that had been identified by ultrasound during the examination in the second trimester as a routine practice for all our screened women.

The findings of the study confirm the prediction that a combination of maternal serum free $\beta$-hCG and PAPP- 
A with NT thickness at 11-14 weeks of gestation would identify about $90 \%$ of trisomy 21 pregnancies for a $5 \%$ false positive rate ${ }^{14}$, which is far superior to the average sensitivity of $65 \%$ achievable by second trimester biochemical screening ${ }^{15}$. The evidence on first trimester screening for trisomy 21 by nuchal translucency and/or biochemical methods was sufficiently well developed to move out of the research phase into routine practice and that the detection rates by first trimester screening would be superior to those obtained with biochemical screening in the second trimester ${ }^{16}$.

This method is being widely adopted in many European countries ${ }^{17}$. In the Czech Republic, however, the Czech Society of Gynecology and Obstetrics and Ministry of Health is proposing a National Screening Program based on the second trimester service in the mean time.

The setting up of first trimester screening in our clinic required little change to our normal prenatal care practice. Since the beginning of 2004, our first trimester ultrasound scans has been part of the every day routine scanning and the introduction of fetal NT thickness scanning was carried out by reorganizing scanning times and did required only minimal additional resources.

It was necessary to organize early booking of pregnant women, as booking for early dating pregnancies was not in our routine practice. The appointment of a counselor in the clinic was no problem as counseling is part of our clinic routine work. The reagent/instrument costs of biochemical screening using this new technology were estimated to be comparable to those for screening in the second trimester.

\section{REFERENCES}

1. Nicolaides KH. Nuchal translucency and other first trimester sonographic markers of chromosomal abnormalities. AJOG 2004; 191:45-67.

2. Cicero S, Bindra R, Rembouskos G, Spencer K, Nicolaides KH Integrated ultrasound and biochemical screening for trisomy 21 at 11 to 14 weeks. Prenat Diagn 2003; 23:306-10.
3. Spencer K, Spencer C, Power M, Dawson C, Nicolaides KH. Screening for chromosomal abnormalities in the first trimester using ultrasound and maternal serum biochemistry in a one stop clinic: A review of three years prospective experience. Br J Obstet Gynaecol 2003; 110:281-6.

4. Schuchter K, Hafner E, Stangl G, Metzenbauer M, Hofinger D, Philipp K. The first trimester 'combined test' for the detection of Trisomy 21e pregnancies in 4939 unselected pregnancies. Prenat Diagn 2002; 22:211-5.

5. Wapner R, Thom E, Simpson J, Pergament E, Silver R, Filkins K. First trimester maternal serum biochemistry and fetal nuchal translucency screening (BUN) study group. First trimester screening for trisomies 21 and 18. N Engl J Med 2003; 349:1405-13.

6. Fetal Medicine Foundation www.fetalmedicine.com. Down's screening at $11-14$ weeks.

7. Sundberg K, Bang J, Smidt-Jensen S, Brocks V, Lundsteen C, Parner J. Randomised study of risk of fetal loss related to early amniocentesis versus chorionic villus sampling. Lancet 1997; 350:697-703.

8. CEMAT Group. Randomised trial to assess safety and fetal outcome of early and mid-trimester amniocentesis. Lancet 1998; 351:242-7.

11. Snijders R, Noble P, Sebire N, Souka A, Nicolaides KH. UK multicentre project on assessment of risk for trisomy 21 by maternal age and fetal nuchal translucency thickness at 10-14 weeks of gestation. Lancet 1999; 18:519-521.

12. Snijders R, Brizot M, Faria M, Nicolaides KH (1995) Fetal exomphalos at 11-14 weeks of gestation. J Ultrasound Med 14:569574.

13. Johnson S, Sebire N, Snijders R, Tunkel S, Nicolaides KH. Ultrasound screening for anencephaly at 10-14 weeks of gestation. Ultrasound Obstet Gynecol 1996; 9:14-16.

14. Nicolaides KH, Campbell S, Gabbe S, Guidetti R. Ultrasound screening for spina bifida: cranial and cerebellar signs. Lancet 1986; 2:72-74.

15. Snijders R, Nicolaides KH. Sequential screening. In: Nicolaides $\mathrm{KH}$, editor. Ultrasound Markers for Fetal Chromosomal Defects. Carnforth, UK: Parthenon Publishing, 1996. p. 109-13.

16. Spencer K, Souter V, Tul N, Snijders R, Nicolaides KH. A screening program for trisomy 21 at $10-14$ weeks using fetal nuchal translucency, maternal serum free B-human chorionic gonadotropin and pregnancy-associated plasma protein-A. Ultrasound Obstet Gynecol 1999; 13:231-7.

17. Wald N, Kennard A, Hackshaw A, McGuire A. Antenatal screening for Down's syndrome. Health Technol Assess 1998; 2, 1-112.

18. Grudzinskas J, Ward R. Screening for Trisomy 21e in the First Trimester. RCOG, 1997; 67-79.

19. Cuckle H, Lith J. Appropriate biochemical parameters in first trimester screening for Trisomy 21e. Prenat Diagn 1999; 19:505512. 